\title{
Full-field electroretinogram recorded with skin electrodes in normal adults
}

\section{Eletrorretinograma de campo total registrado com eletrodos de pele em adultos normais}

Arthur Gustavo Fernandes ${ }^{1}$, Solange Rios Salomão $^{1}$, Josenilson Martins Pereira ${ }^{1}$, Adriana Berezovsky ${ }^{1}$

\begin{abstract}
Purpose: Alternative recording methods have been tested to allow the electroretinogram (ERG) recording in uncooperative patients and/or patients with palpebral alterations, including recordings with skin electrodes. The purpose of this study was to compare ERG recorded with skin electrodes and well-established microfiber electrodes and to determine normative values of ERG parameters for recording with skin electrodes.

Methods: Fifty healthy volunteers (17-26 years; mean $20.63 \pm 2.01$ years) participated in the study. A gold disk skin electrode was placed on the lower orbital rim of a randomly chosen eye. On the contralateral eye, a microfiber electrode was positioned in the lower conjunctival sac. Gold disc electrodes were positioned at the ipsilateral outer canthus of both eyes acting as reference electrodes for the creation of a potential difference. Two ground electrodes were placed on the lobe of each ear. ERGs were recorded according to the International Society of Clinical Electrophysiology Visual (ISCEV) protocol using the VERIS 5.1.9 system for data acquisition and analysis.

Results: Both types of electrodes showed similar wave response morphologies. The implicit time of responses between the two electrodes was comparable. On peak-to-peakamplitude, skin electrode recordings showed an amplitude reduction of $61.4 \%$ for rod responses, $61.5 \%$ for maximal responses, $46.2 \%$ for oscillatory potentials, $57.4 \%$ for cone responses, and $54.4 \%$ for $30 \mathrm{~Hz}$-flicker responses, when compared with microfiber electrode recordings. Based on these findings, normative values for peak-to-peak amplitude and implicit time to be used as a reference for ERGs recorded with skin electrodes were determined.

Conclusions: ERGs recorded with skin electrodes presented lower peak-to-peak amplitude compared with microfiber electrodes. However, using appropriate normative values, skin electrodes may be useful for specific target populations such as uncooperative infants and/or patients with ocular surface alterations.
\end{abstract}

Keywords: Electroretinography; Electrodes; Skin; Eyelids; Comparative study

\section{RESUMO}

Objetivo: O eletrorretinograma de campo total (ERG) em pacientes não colaborativos elou com alterações palpebrais pode ser registrado com diferentes métodos de captação de respostas, dentre eles os eletrodos de pele. O objetivo deste estudo foi comparar o eletroretinograma obtido com eletrodos de pele e eletrodos de microfibra, determinando valores normativos para os parâmetros registrados com eletrodos de pele.

Métodos: Cinquenta voluntários saudáveis (17-26 anos; média 20,63 \pm 2,01) participaram deste estudo. Um eletrodo de cúpula de ouro foi aderido à pele na margem orbital inferior de um dos olhos escolhido ao acaso. No olho contralateral, um eletrodo de microfibra foi posicionado no saco conjuntival inferior. Eletrodos de cúpula de ouro foram posicionados na região lateral de cada olho para a formação da diferença de potencial com o eletrodo ativo. Dois eletrodos terra foram posicionados no lobo de cada orelha. O eletrorretinograma foi registrado de acordo com o protocolo da ISCEV (Sociedade Internacional de Eletrofisiologia Visual), com o sistema VERIS 5.1.9 para aquisição e análise dos registros.

Resultados: Os dois tipos de eletrodos apresentaram morfologias de onda similares. O tempo implícito das respostas foi comparável entre os dois tipos de eletrodo. Os registros feitos com eletrodo de pele quando comparados aos registros com eletrodos de microfibra mostraram reduções na amplitude das ondas, de 61,4\% para resposta de bastonetes, $61,5 \%$ para resposta máxima, 46,2\% para potenciais oscilatórios, 57,4\% para resposta de cones, e 54,4\% para flicker $30 \mathrm{~Hz}$. Baseado nestes resultados, foram determinados valores normativos para amplitude e tempo de implícito para ERGs obtidos com eletrodos de pele.

Conclusões: ERGs registrados com eletrodos de pele apresentam respostas com amplitudes menores quando comparados aos registrados com eletrodos de microfibra. No entanto, usando valores normativos apropriados, os eletrodos de pele podem ser uma alternativa útil para populações especificas como pacientes não colaborativos elou com alterações palpebrais.

Descritores: Eletrorretinografia; Eletrodos; Pele; Pálpebras; Estudo comparativo

\section{INTRODUCTION}

Full-field electroretinogram (ERG) measures the diffuse response of retina cells to a light stimulation. The response is the consequence of light-induced changes in the transretinal movements of ions in the extracellular space, particularly sodium and potassium ${ }^{(1)}$. The electrical activity recorded represents the combination of positive and negative components originated from different stages of retinal processing.

The ERG response is generally expressed as a waveform with negative and positive deflections. The negative deflection, called a-wave, represents the activity of photoreceptors. The positive deflection, called b-wave, represents the ON-bipolar cell function ${ }^{(1)}$. ERG has been used as a diagnostic method for inherited retinal degenerative disea- ses such as retinitis pigmentosa, congenital stationary night blindness, cone dystrophy, and other conditions ${ }^{(2-4)}$. At times, ERG abnormalities can precede fundus changes ${ }^{(5)}$.

Different types of electrodes can be used for ERG recording, and those that contact the cornea or nearby bulbar conjunctiva during the procedure are most strongly suggested for full-field ERG recording. These electrodes include conductive fibers and foils, bipolar contact lenses, conjunctival loop electrodes, and corneal wicks ${ }^{(6)}$. ERG recording in uncooperative patients and/or patients with palpebral alterations is a challenge because of the difficulty of appropriate placement of the conventional active electrodes. Alternative recording methods such as the use of skin electrodes have been tested to allow ERG recording in this specific group of patients.
Submitted for publication: February 25, 2016

Accepted for publication: May 27, 2016

Laboratório de Eletrofisiologia Visual Clínica, Departamento de Oftalmologia e Ciências Visuais, Escola Paulista de Medicina (EPM), Universidade Federal de São Paulo (UNIFESP), São Paulo, SP, Brazil.
Funding: No specific financial support was available for this study.

Disclosure of potential conflicts of interest: None of the authors have any potential conflict of interest to disclose.

Corresponding author: Adriana Berezovsky. Depto. de Oftalmologia e Ciências Visuais. Rua Botucatu, 821 - São Paulo, SP - 04023-062 - Brazil - E-mail: aberezovsky@unifesp.br

Approved by the following research ethics committee: Universidade Federal de São Paulo - UNIFESP (\#0174/04). 
The objective of this study was to compare the ERG recorded with skin electrodes and well-established microfiber active electrodes. In addition, normative values for ERG parameters recorded with skin electrodes were determined.

\section{METHODS}

This study protocol was evaluated by the Committee of Ethics in Research of the Universidade Federal de São Paulo and was approved in accordance with the principles of the Declaration of Helsinki.

\section{Participants}

Healthy volunteers were recruited from university students and employees of Federal University of Sao Paulo and were invited for the full-field ERG test after a full explanation of the procedure, its benefits and risks, followed by written informed consent. The inclusion criteria consisted of normal visual acuity for distance 0.0 logMAR (20/20) or better, lack of visual disorders, normal fundoscopy, and acceptance of the informed consent form. Exclusion criteria consisted of high ametropia (myopia $=-4.00$ spherical equivalent; hyperopia $=+4.00$ spherical equivalent), history of previous ocular surgeries, or hereditary eye diseases.

\section{VISUAL ACUITY}

Presenting visual acuity (with spectacles if used) was measured for each eye using a logMAR chart at $4 \mathrm{~m}$.

\section{FULL-FIELD ERG}

Full-field ERG was performed in a completely dark room, after maximal pupil dilatation (minimum pupil diameter of $6 \mathrm{~mm}$ ) with one drop each of $1 \%$ tropicamide and $10 \%$ phenylephrine hydrochloride, followed by 30 min of dark adaptation.

The Veris electrodiagnostic system (Veris 5.1.9; Electro-Diagnostic Imaging, Sao Mateo, CA, EUA) was used for the ERG recording. Peak-to-peak amplitudes were measured in microvolts $(\mu \mathrm{V})$, and the implicit time was measured in milliseconds (ms).

A skin electrode (Grass Gold Disc Electrodes-E5GH) was placed on the lower orbital rim of a randomly chosen eye. On the contralateral eye, an active microfiber electrode was positioned in the lower conjunctival sac (Figure 1). Gold disc electrodes were positioned at the ipsilateral outer canthus of both eyes acting as reference electrodes for the creation of a potential difference. Two ground electrodes were placed on the lobe of each ear.

ERGs were recorded according to the International Society of Clinical Electrophysiology Visual (ISCEV) protocol(7), which is considered the minimum requisite for comparison of different tests performed in different centers ${ }^{(8)}$.

The participants were adapted to complete dark condition for 30 min, and the protocol of ERG recording followed this sequential order: (a) Rod response (a maximum intensity white light with a $2.4 \mathrm{log}$ neutral density filter attenuation); (b) Maximal response (a maximum intensity white light to obtain a combined response of cones and rods after dark-adaptation); (c) Oscillatory potentials (a maximum intensity white light with a $75-\mathrm{Hz}$ low-cut and $500-\mathrm{Hz}$ high-cut filter); and a maximum intensity white light in a $30 \mathrm{~cd} / \mathrm{m}^{2}$ background presented at (d) $1 \mathrm{~Hz}$ and (e) $30 \mathrm{~Hz}$ to obtain cone responses after a $10 \mathrm{~min}$ adaptation to a $30 \mathrm{~cd} / \mathrm{m} 2$ background light (d) single-flash cone response (maximum intensity light at $1 \mathrm{~Hz}$ ) and (e) $30 \mathrm{~Hz}$ flicker response (maximum intensity light at $30 \mathrm{~Hz}$ ) were recorded.

Figure 2 shows a representative full-field ERG recording from a 22-year-old male participant. Right eye responses were recorded with the microfiber electrode, and left eye responses were recorded with the skin electrode.

\section{Statistical analysis}

Peak-to-peak amplitude and implicit time from each step of the ISCEV standard ERG protocol were compared between the microfiber electrode and the skin electrode using a statistical package (Jandel Sigmastat-Statistical Software Version 2.0, USA). The significance level used was 0.05. All the parameters were compared between the electrodes using the Mann-Whitney rank sum test. Normative values for skin electrode full-field ERG recordings were calculated as 2.5 and 97.5 percentiles of peak-to-peak amplitude and implicit time.

\section{RESULTS}

A total of 50 normal subjects (17-26 years; mean $20.63 \pm 2.01$ years; 19 males) were recruited for the study based on the inclusion criteria.

Mean amplitudes and implicit times for the five ERG responses are shown in table 1; figure 3 shows the comparison of the recordings of the microfiber electrodes and the skin electrodes. All responses showed similar waveforms for both the electrodes. There was no statistical difference in the implicit time of responses between the two types of electrodes. On amplitude, skin electrode responses showed a significant amplitude reduction ( $p<0.001$ ) of $61.4 \%$ for rod responses, $61.5 \%$ for maximal responses, $46.2 \%$ for oscillatory potentials, $57.4 \%$ for cone responses, and $54.4 \%$ for flicker responses, when compared with microfiber electrode responses.

Based on these results, normative values for amplitude and implicit time to be used as a reference for full-field ERG recorded with skin electrodes were determined as shown in table 2.

\section{DISCUSSION}

ERG recordings using skin electrodes produced lower amplitudes and higher electrical noise. This technique is not recommended by ISCEV; however, it can be adopted for specific clinical conditions ${ }^{(7)}$. In this study, it was observed that when using skin electrodes as an alternative method, the responses present similar wave morphology and had no significant difference regarding implicit times for all five ISCEV protocol responses.

The reduction found in peak-to-peak amplitudes recorded with skin electrodes in our study is consistent with previous reports of reductions of $75 \%$ and $80 \%{ }^{(9)}, 43 \%-73 \%(10), 50 \%-70 \%(11), 50 \%(12), 23 \%-62 \%(13)$, and $42 \%-57 \%{ }^{(14)}$. Our data showed reductions between $46 \%$ and $62 \%$ on the peak-to-peak amplitudes. Physical factors are involved in this reduction given their influence on the current flow through the electrodes. Such factors include the resistive and capacitative characteristics of the materials from which the electrodes are made and coated with and the area of the recording surface. In addition, the amplitude recorded with skin electrodes is noisier, mainly as a result of electromyographic activity intervention ${ }^{(15)}$. However, it has been shown that even with reduced amplitudes, recordings with skin electrodes can be useful to differentiate between normal and abnormal responses, as long as an appropriate normative reference is used ${ }^{(16)}$. The combination of clinical
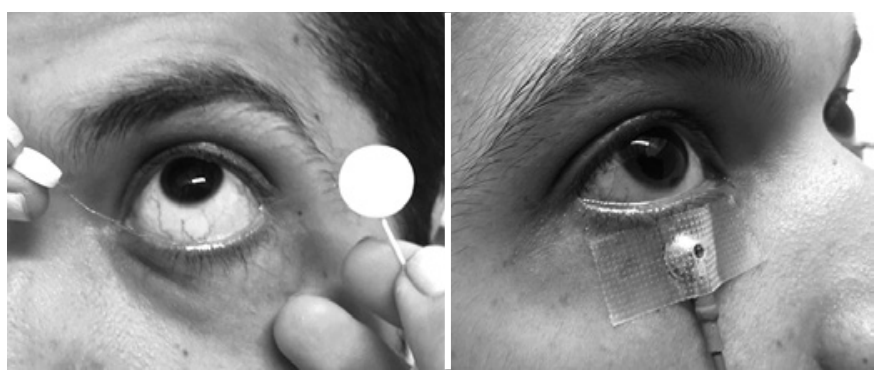

Figure 1. Electrode placement (microfiber electrode/skin electrode) 


\section{Full field ERG}

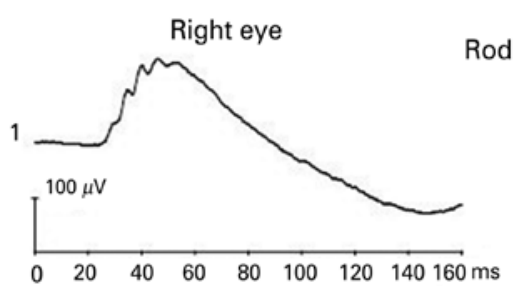

Left eye

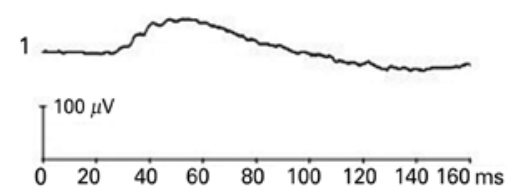

Maximal response
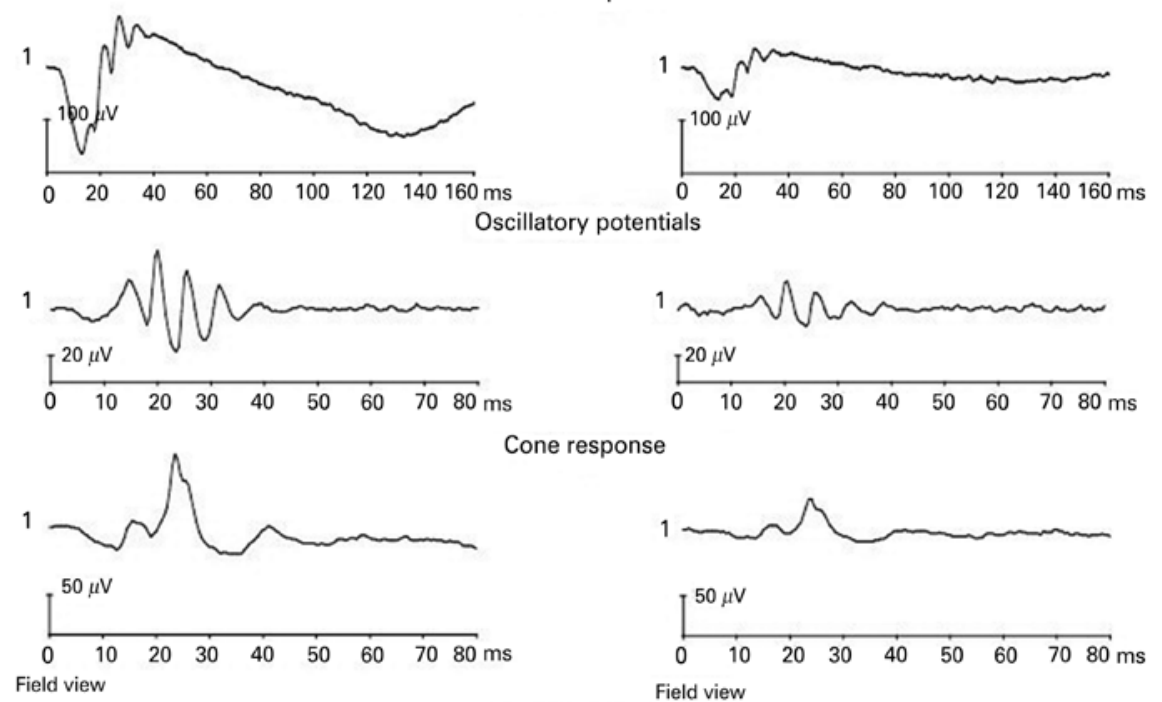

Field view

Flicker $30 \mathrm{~Hz}$
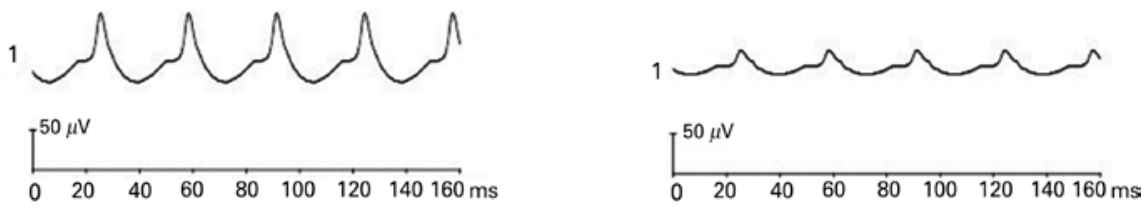

Figure 2. ERG recording from a 22-year-old male (OD: microfiber electrode/OS: skin electrode).

Table 1. Amplitude and implicit time measurements for microfiber electrodes and skin electrodes

\begin{tabular}{|c|c|c|}
\hline \multicolumn{3}{|c|}{$\begin{array}{c}\text { Peak-to-peak amplitudes of the standardized ERG recorded with } \\
\text { microfiber electrodes and skin electrodes }\end{array}$} \\
\hline & Microfiber electrode & Skin electrode \\
\hline Rod response & $198.49 \pm 40.30 \mu \mathrm{V}$ & $81.60 \pm 17.88 \mu \mathrm{V}$ \\
\hline Maximal response & $276.27 \pm 48.86 \mu \mathrm{V}$ & $114.14 \pm 22.30 \mu \mathrm{V}$ \\
\hline Oscillatory potentials & $90.31 \pm 49.56 \mu \mathrm{V}$ & $49.61 \pm 32.56 \mu \mathrm{V}$ \\
\hline Cone response & $108.66 \pm 32.02 \mu \mathrm{V}$ & $47.42 \pm 13.36 \mu \mathrm{V}$ \\
\hline Flicker $30 \mathrm{~Hz}$ & $50.86 \pm 20.73 \mu \mathrm{V}$ & $24.27 \pm 9.00 \mu \mathrm{V}$ \\
\hline b/a ratio & $1.95 \pm 0.42$ & $1.76 \pm 0.26$ \\
\hline \multicolumn{3}{|c|}{$\begin{array}{l}\text { Implicit time of the standardized ERG recorded with } \\
\text { microfiber electrodes and skin electrodes }\end{array}$} \\
\hline & Microfiber electrode & Skin electrode \\
\hline Rod response & $55.27 \pm 8.97 \mathrm{~ms}$ & $53.77 \pm 8.54 \mathrm{~ms}$ \\
\hline Maximal response & $36.17 \pm 6.15 \mathrm{~ms}$ & $33.25 \pm 5.48 \mathrm{~ms}$ \\
\hline Cone response & $25.03 \pm 2.77 \mathrm{~ms}$ & $24.79 \pm 2.59 \mathrm{~ms}$ \\
\hline Flicker $30 \mathrm{~Hz}$ & $27.04 \pm 2.42 \mathrm{~ms}$ & $26.55 \pm 2.73 \mathrm{~ms}$ \\
\hline
\end{tabular}

findings and ERG results demonstrated that ERGs with skin electrodes are accurate for the diagnosis of retinal dystrophies ${ }^{(16)}$.

For pediatric patients, ERG recorded with skin electrodes presents an important advantage because there is no need for sedation. In patients with ocular surface alterations, this technique is suggested as a unique alternative for recording ERG.

Consideration of pediatric age groups could have provided better evaluation of the electrode performance; however, several studies report that peak-to-peak amplitudes of ERG responses are similar in children and adults, irrespective of whether recording is performed with conventional or skin electrodes ${ }^{(17-21)}$. ERG responses are said to achieve adult levels by the fourth year of life; therefore, separate pediatric normative values evaluation would be necessary for children aged $<4$ years ${ }^{(6)}$.

Previous studies with skin electrodes have demonstrated that peak-to-peak amplitude can show variability as the skin electrode can move during the exam, reducing the amplitudes on the final steps as the electrodes lose adherence to the skin ${ }^{(11)}$. However, comparative studies demonstrated that the variability found with skin electrodes is similar to the variability found with corneal contact electrodes, and examiners need to ensure that the electrode is correctly placed close to the lower orbital rim during the entire exam ${ }^{(9,22)}$. 


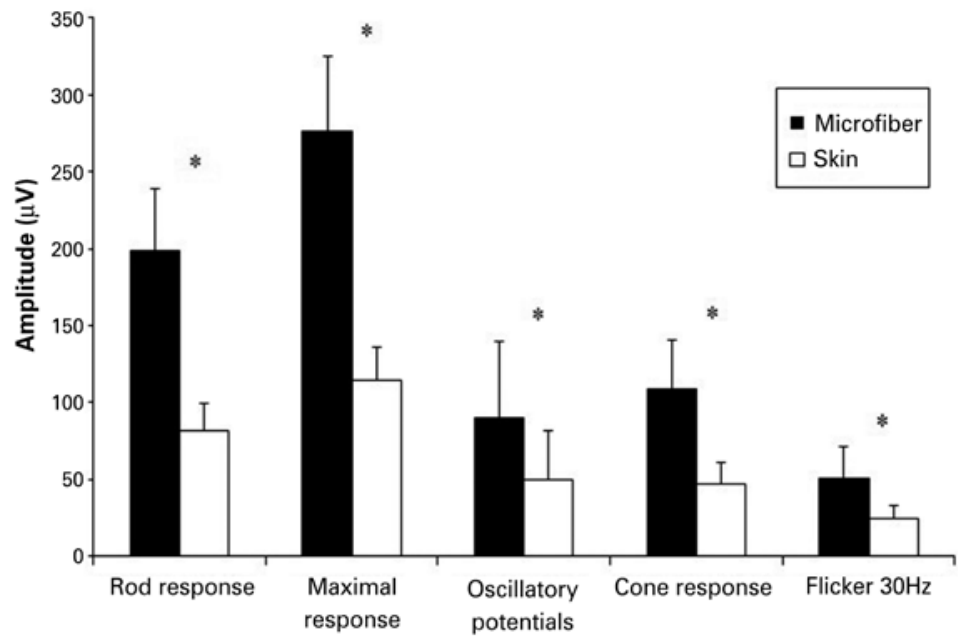

${ }^{*}$ significant difference $p<0.001$

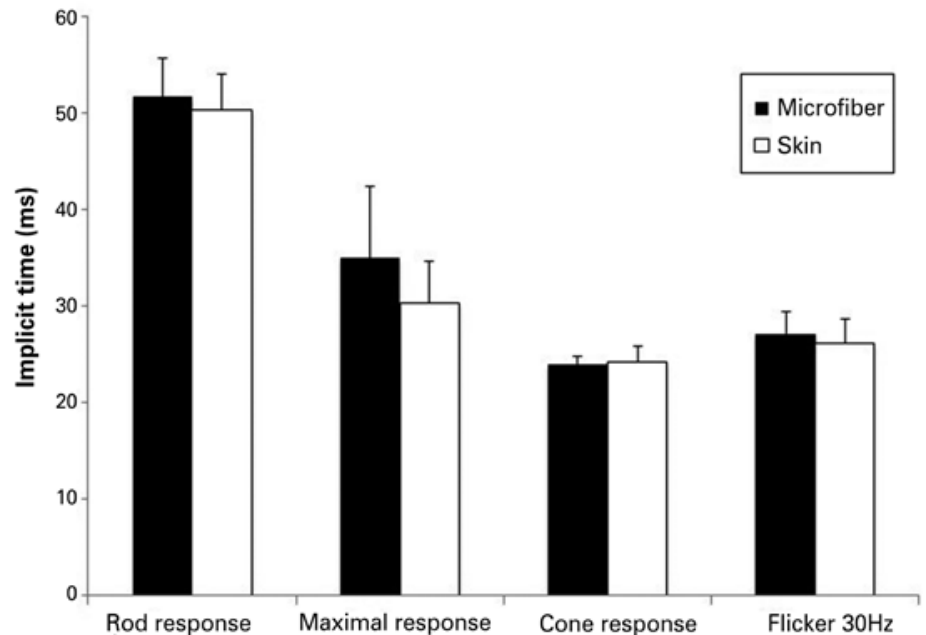

Figure 3. Mean amplitude and implicit time comparison between microfiber electrodes and skin electrodes ( $\left.{ }^{*} p<0.001\right)$. Error bars represent standard deviation of the mean.

Table 2. Normative values (2.5 and 97.5 percentiles) for full-field ERGs obtained with skin electrodes

Normative values for peak-to-peak amplitude for responses recorded with skin electrodes

\begin{tabular}{lc}
\hline Rod response & $45.70-112.31 \mu \mathrm{V}$ \\
Maximal response & $68.82-154.39 \mu \mathrm{V}$ \\
Oscillatory potentials & $15.05-137.51 \mu \mathrm{V}$ \\
Cone response & $19.35-74.19 \mu \mathrm{V}$ \\
Flicker $30 \mathrm{~Hz}$ & $11.19-45.56 \mu \mathrm{V}$ \\
b/a ratio & Normative values for implicit time for \\
\hline & responses recorded with skin electrodes \\
\hline Rod response & $43.84-75.38 \mathrm{~ms}$ \\
Maximal response & $25.50-44.98 \mathrm{~ms}$ \\
Cone response & $22.00-30.65 \mathrm{~ms}$ \\
Flicker $30 \mathrm{~Hz}$ & $24.00-33.69 \mathrm{~ms}$ \\
\hline
\end{tabular}

The ISCEV protocol and the recommendation for each laboratory to determine its own normative values are extremely important for a high quality test. Normative values from different laboratories may differ for several reasons including different equipment, different electrodes, and different settings on the Ganzfeld ${ }^{(23)}$.

Testing using skin electrodes for full-field ERG recording in patients previously diagnosed with retina dystrophy using ERG with conventional electrodes is recommended to allow an evaluation of the validity of the results and accuracy of the skin electrodes as an alternative method.

Our findings are comparable to previous studies, indicating a reduction in amplitude of electroretinography responses recorded with skin electrodes. However, skin electrodes are useful for specific target populations such as uncooperative infants and/or patients with ocular surface alterations. The normative values calculated in this study can be used as a reference for full-field ERG recorded with skin electrodes.

\section{REFERENCES}

1. Gundogan FC, Tas A, Sobaci G. Electroretinogram in hereditary retinal disorders [Internet]. In: Belusic G. Electroretinograms. INTECH Open Access; 2011. [cited 2015 Jul 27]. 
Available from: http://www.intechopen.com/books/electroretinograms/electroretinogram-in-hereditary-retinal-disorders.

2. Birch DG. Clinical electroretinography. In: Fuller DG, Birch DG, editors. Assessment of visual function for the clinician. Ophthalmol Clin North Am. 1989;2:469-98.

3. Paranhos FR, Avila MP, Paranhos A, Cialdini AP. Estudo estatístico de valores normais do eletrorretinograma: contribuição à padronizaçäo do exame. Arq Bras Oftalmol. 1997; 60(3):278-84

4. Birch DG, Anderson JL. Standardized full-field electroretinography: normal values and their variation with age. Arch Ophthalmol. 1992;110(11):1571-6.

5. Pereira JM, Mendieta L, Sacai PY, Salomão SR, Berezovsky A. Estudo normativo do eletrorretinograma de campo total em adultos jovens. Arq Bras Oftalmol. 2003;66(2):137-44.

6. Papathanasiou ES, Papacostas SS. Flash electroretinography: normative values with surface skin electrodes and no pupil dilation using a standard stimulation protocol. Doc Ophthalmol. 2008;116(1):61-73.

7. McCulloch DL, Marmor MF, Brigell MG, Hamilton R, Holder GE, Tzekov R, et al. ISCEV Standard for full-field clinical electroretinography (2015 update). Doc Ophthalmol. 2015; 130(1):1-12.

8. Berezovsky A, Pereira JM, Salomão SR, Santos VR, Schor P. Validation of a new fiber electrode prototype for clinical electroretinography. Arq Bras Oftalmol. 2008;71(3): 316-20.

9. Bradshaw K, Hansen R, Fulton A. Comparison of ERGs recorded with skin and cornealcontact electrodes in normal children and adults. Doc Ophthalmol. 2004;109(1):43-55.

10. Stevens T. Electrophysiologic testing in disorders of the retina, optic nerve, and visual pathway. (Ophthalmology Monographs, No. 2). Arch Ophthalmol. 2001;119(11):1734.

11. Kriss A. Skin ERGs: their effectiveness in paediatric visual assessment, confounding factors, and comparison with ERGs recorded using various types of corneal electrode. Int J Psychophysiol. 1994;16(2):137-46.

12. Hawlina M. Pattern electroretinography with the new HK-loop electrode. Chibret Int J Ophthalmol. 1993;9:51-8
13. Mortlock KE, Binns AM, Aldebasi YH, North RV. Inter-subject, inter-ocular and inter-session repeatability of the photopic negative response of the electroretinogram recorded using DTL and skin electrodes. Doc Ophthalmol. 2010;121(2):123-34.

14. Hamilton R, Al Abdlseaed A, Healey J, Neveu M, Brown L, Keating D, et al. Multi-centre variability of ISCEV standard ERGs in two normal adults. Doc Ophthalmol. 2015;130(2): 83-101.

15. Esakowitz L, Kriss A, Shawkat F. A comparison of flash electroretinograms recorded from Burian Allen, JET, C-glide, gold foil, DTL and skin electrodes. Eye (Lond). 1993;7 (Pt 1):169-71.

16. Meredith S, Reddy M, Allen L, Moore A, Bradshaw K. Full-field ERG responses recorded with skin electrodes in pediatric patients with retinal dystrophy. Doc Ophthalmol. 2004; 109(1):57-66.

17. Fulton AB, Hansen RM, Westall CA. Development of ERG responses: the ISCEV rod maximal and cone responses in normal subjects. Doc Ophthalmol. 2003:107(3):235-41.

18. Westall CA, Panton CM, Levin AV. Time courses for maturation of electroretinogram responses from infancy to adulthood. Doc Ophthalmol. 1998;96(4):355-79.

19. Fulton $A B$, Hansen RM. Electroretinography: application to clinical studies of infants. J Pediatr Ophthalmol Strabismus. 1985;22(6):251-5.

20. Breton ME, Quinn GE, Schueller AW. Development of electroretinogram and rod phototransduction response in human infants. Invest Ophthalmol Visual Sci. 1995;36(8): $1588-602$

21. Fulton $A B$, Hansen RM. The development of scotopic sensitivity. Invest Ophthalmo Visual Sci. 2000;41(6):1588-96.

22. Wali N, Leguire LE. Dark-adapted luminance-response functions with skin and corneal electrodes. Doc Ophthalmol. 1991;76(4):367-75.

23. Jacobi PC, Miliczek K, Zrenner E. Experiences with the international standard for clinica electroretinography: normative values for clinical practice, interindividual and intraindividual variations and possible extensions. Doc Ophthalmol. 1993;85(2):95-114.

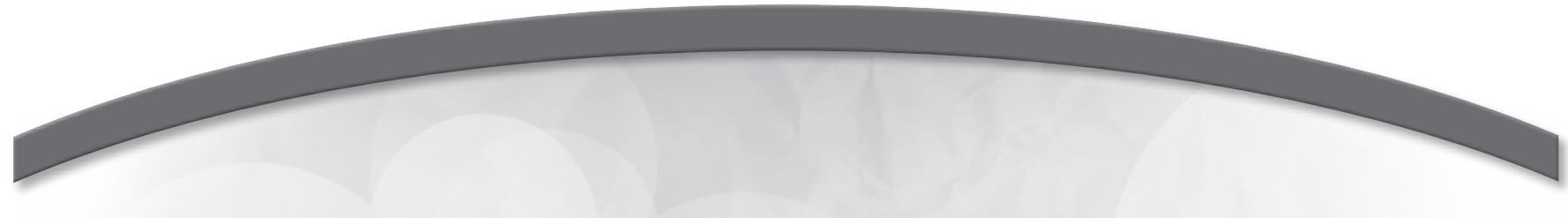

\title{
Jornada Internacional de Atualização em Oftalmologia Pediátrica - SBOP 2017
}

\author{
16 e 17 de junho de 2017
}

São Paulo - SP 